\title{
PANDAS Hipotezi
}

\author{
Hasan Cenk MíRZA \\ Merzifon Devlet Hastanesi, Mikrobiyoloji Laboratuvart
}

\section{ÖZET}

Illk kez. Swedo ve arkadaşlart tarafindan 1998 yılında tanımlanan "streptokok ile ilişkili pediatrik otoimmün nöropsikiyatrik bozukluklar (PANDAS)" terimi, otoimmün temeli olduğu ve A grubu beta-hemolitik streptokoklar tarafindan tetiklendiğ $i$ düşünülen çocukluk ça $\breve{g} l$ nöropsikiyatrik bozukluklarını [obsesif-kompulsif bozukluklar ve tik bozuklukları] ifade etmek için kullanılmaktadır. PANDAS hipotezinin iyi tanımlanmış, özgül bir klinik

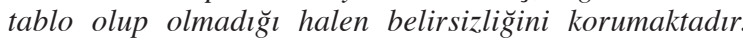
Zira diğer mikrobiyal etkenlerin de (viruslar ve diğer bakteriler) obsesif-kompulsif bozukluklar ve tik bozukluklarıyla ilişkisi gösterilmiştir. Ayrıca PANDAS tanı kriterleri içerisinde yer almayan "anoreksiya nervoza" ve "akut dissemine ensefalomiyelit (ADEM)" gibi psikiyatrik ve nörolojik bozuklukların da A grubu beta-hemolitik streptokok enfeksiyonlarıla ilişkisi gösterilmiştir. A grubu beta-hemolitik streptokoklar ile semptomlar arasindaki iliskileri, PANDAS'ın immünolojik temelini ve PANDAS'taki tedavi seçeneklerini araştıran çalışmaların sonuçlarında tutarsizlıklar olduğu görülmektedir. Zira PANDAS hakkında şu ana kadar elde edilen bilgiler genellikle görece küçük, retrospektif çalışmalar ve olgu raporlarına dayanmaktadır. PANDAS tanımının ve tanı kriterlerinin yeniden şekillendirilmesine olanak verecek, daha geniş, iyi dizayn edilmiş, prospektif çalışmalara gereksinim duyulmaktadır. Bu derlemede PANDAS'ın etiyolojisi, patogenezi, immünolojik boyutu, klinik bulgular ve tedavi seçenekleri tartışılmıştır.

Anahtar kelimeler: Streptokok, tik bozukluğu, PANDAS

\section{SUMMARY}

\section{PANDAS Hypothesis}

The term "pediatric autoimmune neuropsychiatric disorders associated with streptococcal infections (PANDAS)" which was first defined by Swedo et al. in 1998, has been used to express the childhood neuropsychiatric disorders [obsessivecompulsive disorders and tic disorders] that are thought to have an autoimmune basis and to be triggered by group A beta-hemolytic streptococci. It is still unclear whether PANDAS hypothesis is a well-defined, isolated clinical entity because other infectious agents like viruses and other bacteria have also been reported to be associated with obsessive-compulsive disorder or tic disorders. Also psychiatric and neurological pathologies such as "anorexia nervosa" and "acute disseminated encephalomyelitis" which were not included in the diagnostic criteria of PANDAS have been shown to be associated with group A beta-hemolytic streptococci infections. Inconsistencies have been seen in the results of the studies which investigated the association between group A beta-hemolytic streptococci and symptoms, immune-mediated basis of PANDAS and the treatment options in PANDAS represent. So far, the information about PANDAS is often derived from relatively small, retrospective, uncontrolled studies or case reports. Larger, well-designed, prospective studies are necessary to remodelling the definition and diagnostic criteria of PANDAS. In this review etiology, pathogenesis, immunology, clinical signs and treatment options of PANDAS were discussed.

\section{Gíiș}

A grubu beta-hemolitik streptokoklar (AGBHS) bakteri kaynakli tonsillofarenjitlerin en sık nedenidirler ${ }^{(1)}$. Bunun yanında deri ve yumuşak doku enfeksiyonlarına da neden olmaktadırlar. Sahip oldukları birçok virulans faktörü (M ve F proteinleri, streptolizin $\mathrm{O}$ ve $\mathrm{S}$, streptokinaz, hyalüronidaz, vb.) bu enfeksiyonları oluşturmalarında rol oynamak$\operatorname{tad} 1 \mathrm{r}^{(2)}$.
Key words: Streptococcus, tic disorder, PANDAS

Oluşturdukları enfeksiyon dışı klinik tablolar [akut romatizmal ateş (ARA), glomerülonefrit] nedeniyle, AGBHS'ler mikroorganizmalar içerisinde ayrı bir öneme sahiptirler. Bu klinik tabloların, AGBHS'lerin bazı antijenik yapılarının vücut antijenleriyle benzeşmesi, dolayısıyla AGBHS'lere karşı vücut tarafından oluşturulan antikorların vücuttaki bazı yapılara karşı çapraz reaksiyon göstermesi nedeniyle oluştuğu sanılmaktadır. Örneğin, ARA'nın majör kriterlerinden birisi olan 'Sydenham koresi' oluşumunda 
streptokok enfeksiyonu sonrası meydana gelen ve bazal ganglionları hedef alan antikorların etkisinin olduğu bildirilmektedir ${ }^{(3)}$. Sydenham koresi; ekstremite uçlarında amaçsız, istemsiz ani hareketler, kas güçsüzlüğü, koordinasyon güçlüğü ve duygusal değişkenlikle karakterizedir.

\section{TARİHÇE}

Sydenham koresi ilk olarak 1686 y1lında İngiliz hekim Thomas Sydenham tarafindan tanımlanmıştır. Sir William Osler ise, günümüzden bir asırdan uzun bir süre önce Sydenham koreli hastalarda "yineleyici davranışları" tanımlamıştır. Sydenham koresinin gidişi sırasında sıklıkla obsesif-kompulsif belirtilerin ortaya çıktığı bildirilmektedir $^{(4)}$.

Swedo ve ark..$^{(5)}$, Sydenham koresinin oluşum mekanizması ile benzer mekanizma sonucu oluştuğuna inandıkları ve "streptokok ile ilişkili pediatrik otoimmün nöropsikiyatrik bozukluklar (PANDAS)" olarak adlandırdıkları bir terimi gündeme getirmiş, 1998 y1lında ilk 50 PANDAS olgusunu yayınlamışlardır.

\section{Etiyoloji ve Patogenez}

A grubu beta-hemolitik streptokok enfeksiyonu sonrası Sydenham koresi oluşumunun patogenezi tam olarak bilinmemekle birlikte, en çok kabul edilen görüş "moleküler taklit mekanizması"dır ${ }^{(6)}$. Zira streptokokların hücre membranlar1 ile santral sinir sistemindeki (SSS) nucleus caudatus ve nucleus subthalamicus arasinda çapraz reaksiyonların varlığı gösterilmiştir ${ }^{(7)}$.

Kirvan ve ark. ${ }^{(6)}$, Sydenham koreli hastalardan elde edilen ve streptokokların hücre duvarında bulunan $\mathrm{N}$-asetil-beta-D-glukozamin (GlcNAc) karbonhidratını hedef alan monoklonal antikorların, insan santral sinir sistemindeki lizogangliozid GM1 ile çapraz reaksiyon verdiğini göster- mişlerdir. Lizogangliozid GM1'in nöronal sinyal transdüksiyonunda etkili olduğu bilinmektedir. Aynı çalışmada bu antikorların kalsiyum/kalmodulin bağımlı protein kinazı (Cam Kinaz II) aktifleştirdiği gösterilmiştir. Cam Kinaz II'nin ise davranış, öğrenme, hafıza, nörotransmitter sentezi ve salınımında fonksiyon gösterdiği bilinmektedir.

Sydenham koreli hastaların plazmaferez, intravenöz immünoglobulin (IVIG) ve kortikosteroid gibi immünomodülatör tedavilerden yarar görmesi, hastalığın immün sistem kaynaklı sorunlar nedeniyle geliştiğini doğrular niteliktedir ${ }^{(8)}$.

Swedo ve ark. ${ }^{(5)}$, Sydenham koresinin gelişim mekanizmasını, PANDAS için örnek bir model olarak almış; etiyolojik ajanın dozunun kore gelişimine neden olacak kadar yeterli olmadiğ 1 durumda, çocuklarda yalnızca tikler ve obsesifkompulsif bozuklukların (OKB) ortaya çıkabileceğini öne sürmüşlerdir.

PANDAS kriterlerine uyan hastalarda antinöronal antikor varlığgnın araştırıldığ 1 farklı çalışmalarda farklı sonuçlar elde edilmiş̧tir. Antinöronal antikorların varlığını gösteren çalışmaların $^{(9,10)}$ yanı sıra bu antikor düzeylerinin PANDAS tanılı hastalar ile kontrol gruplarında anlamlı farklılık göstermediğini bildiren çalışmalar da mevcuttur ${ }^{(11,12)}$. Bu farklılıkların nedenlerinden birisinin metodolojik olabileceği düşünülmektedir (insan nöral antijeni yerine tavşan nöral antijeni kullanılması; antijen hazırlama veya antikor saptamada farklı yöntemlerin kullanılması gibi). Anti-nöronal antikorların araştırıldığ 1 çalışmalarda elde edilen farklı sonuçlar PANDAS hipotezinin doğruluğu konusunda şüphe uyandırmakla birlikte, PANDAS tanısı konan hastaların IVIG, plazma değişimi gibi tedavilerden yarar görmesi, bu hipotezde immün sistemin rolü olduğunu düşündürmektedir $^{(13)}$. 


\section{Hastalığın immünolojik boyutu}

Sydenham koresinde olduğu gibi, PANDAS'ta da AGBHS enfeksiyonu tarafından tetiklenen otoimmün mekanizmaların rolü olduğu sanılmaktadır. AGBHS antijenlerine maruz birakılan kobaylarda meydana gelen immünolojik yanıtın incelendiği çalışmalar mevcuttur.

Hoffman ve ark. ${ }^{(14)}$ bir grup kobayın deri altına AGBHS homojenatı enjeksiyonu yapmışlardır. Belirli bir süre sonunda bu kobaylardan aldıkları serumu, yine kobay beyni ile muamele etmişlerdir. AGBHS homojenatı enjeksiyonu yapılmayan kontrol grubu kobayların serumlarının hiç birisi, beynin herhangi bir bölgesinde immünolojik bir reaksiyona neden olmamıştır. Fakat AGBHS homojenatı enjeksiyonu yapılan kobayların bir kısmının serumları beynin "derin serebellar çekirdek, globus pallidus ve talamus" bölgelerinde immünolojik reaksiyona neden olmuştur. Ayrıca Hoffman ve ark. ${ }^{(14)}$ bu çalışmalarında, serumlarında "derin serebellar çekirdek"e karşı antikor saptanan kobayların beyinlerindeki "derin serebellar çekirdek" bölgesinde IgG antikorlarının birikimini göstermişler; bu bölgedeki antikor birikimi ile kobaylarda meydana gelen davranış değişiklikleri arasındaki ilişkiye de dikkat çekmişlerdir.

Kobaylarda yapılan bir başka çalışmada ${ }^{(15)}$, AGBHS antijenleri verilerek bağ 1 şık yanıt oluşturulan kobayların serumları nöron hücreleri ile muamele edildikten sonra, nöron hücrelerinde artmış Cam Kinaz II aktivitesi gözlenmiştir. Kobayların serumlarının anti-IgG antikorlarıyla muamelesinden sonra bu aktivitenin azaldı $\breve{g} 1$ tespit edilmiştir. Yine bu çalışmada, AGBHS antijenleri verilerek bağışık yanıt oluşturulan kobayların beyinlerinde, kontrol grubuna göre dopamin düzeyinin artmış, glutamat düzeyinin ise azalmış olduğu saptanmıştır. Ayrıca bu kobayların serumlarının insan dopamin reseptörü (D1 ve D2) antijenleri ile, kontrol grubu serumlarından daha şiddetli immünolojik reaksiyon oluşturduğu, ELISA yöntemi ile tespit edilmiştir. Bu immünolojik reaksiyon "Western Blot" yöntemiyle de doğrulanmıştır. Aynı çalışmada Sydenham koreli ve PANDAS tanılı hastaların serumlarındaki IgG antikorlarının da, kobaylarda gözlendiği gibi kontrol grubuna göre dopamin reseptör antijenleriyle daha şiddetli immünolojik reaksiyona neden olduğu gösterilmiştir. AGBHS antijenlerine maruz kalan kobayların çeşitli motor semptomlar ve kompulsif davranışlar gösterdiği de bu çalışmada vurgulanan noktalar arasındadır.

Şu ana kadar yapılan çalışmalar 1şı̆̆ında Sydenham koresinde, AGBHS enfeksiyonu sonrası oluşan bazı antikorların nöron hücreleri yüzeyinde bulunan antijenlere bağlanarak, bu hücrelerde Cam Kinaz II'yi aktifleştirebildiği düşünülmektedir. Cam Kinaz II aktivasyonunun nöron hücrelerinden dopamin salınımına neden olabileceği, dopaminin de hareket bozukluklar1na neden olabileceği düşünülmektedir ${ }^{(16)}$. Sydenham koresi oluşumu, PANDAS için de bir model teşkil ettiği için, bu mekanizmanın PANDAS'ta da geçerli olabileceği sanılmaktadır.

Bir B lenfosit yüzey belirteci olan D8/17'nin ekspresyonundaki artışın, ARA gelişimi için bir risk faktörü olduğundan bahsedilmektedir ${ }^{(4)}$. PANDAS ile, ARA'nın majör kriterlerinden birisi olan "Sydenham koresi”nin benzer mekanizmalar nedeniyle oluştuğu hipotezinden yola çıkılarak, D8/17 belirtecinin OKB ve tik bozukluğu olan hastalarda araştırıldığı çalışmalar yapılmıştır. PANDAS tanılı 27, Sydenham koreli 9 hasta ile 24 kişilik sağlıklı kontrol grubunun dâhil edildiği bir çalışmada, D8/17 pozitiflik oranı PANDAS, Sydenham koresi ve kontrol gruplarında sirasıyla $\% 85, \% 89$ ve $\% 17$ olarak bulunmuştur $^{(17)}$. Çocukluk çağı başlangıçlı OKB ve/veya Tourette sendromu (bir çeşit tik bozukluğu) bulunan 31 hasta ile 21 kişilik kontrol grubunun dâhil edildiği bir başka çalışmada; 
hastalardaki D8/17 pozitifliği oranının kontrol grubuna göre anlamlı derecede yüksek olduğu belirtilmiştir ${ }^{(18)}$. Yapılan bazı çalışmalarda ise D8/17 belirteci pozitifliği ile OKB ve tik bozukluğu arasında bir ilişki bulunmamıştır ${ }^{(19,20)}$. D8/17 belirteci taşıyan B lenfositlerini saymada kullanılan yöntemlerin farklılık göstermesi (Floresan mikroskopi veya akım sitometrisi gibi), D8/17 belirtecini saptamada kullanılan "IgM tipindeki monoklonal antikorun" moleküler yapısının stabil olmaması ve bu antikorun ticari olarak kullanıma sunulmaması gibi faktörlerin, çalışmaların sonuçları arasındaki farklılıkların nedenlerinden bazıları olduğu düşünülmektedir. Çalışmalarda standart yöntemler ve daha yüksek sayıda hasta ile kontrol gruplarının kullanılması, D8/17 belirteci ile ilgili daha sağlıklı sonuçlara ulaşılmasını sağlayabilecektir.

\section{Nörogörüntüleme}

Sydenham koreli hastalar ile PANDAS tanılı hastaların santral sinir sisteminde meydana gelen değissiklikleri görüntülemek amacıyla yapılan sınırlı sayıda radyolojik çalışma mevcuttur. Çalışmaların çoğunda Sydenham koreli hastalarda patolojik manyetik rezonans görüntüleme (MRG) değişikliği gözlenmemiştir ${ }^{(21)}$. Bunun yanında Sydenham koreli hastalar ile PANDAS tanılı hastalarda nucleus caudatus, putamen ve globus pallidus boyutlarının kontrol gruplarına göre daha büyük olduğunun gösterildiği çalışmalar da vardır ${ }^{(22,23)}$. Bazal ganglionlardaki bu boyut artışının, immün yanıt sonrası meydana gelen reaksiyon sonucu oluştuğu düşünülmektedir.

\section{PANDAS TANI KRITERLERİ ve KLINIIK}

Swedo ve ark. ${ }^{(5)} 1998$ y1lında, 50 adet PANDAS olgusunu tanımladıkları çalışmada, PANDAS için 5 adet tanı kriterinden söz etmiştir. PANDAS tanı kriterleri Tablo 1'de gösterilmiştir. Bu kriterleri taşıyan 50 olgu retrospektif olarak değerlendirildiğinde, PANDAS'ın her iki cinste de
Tablo 1. PANDAS tanı kriterleri.

1. Obsesif-kompulsif bozukluk veya bir tik bozukluğunun bulunmasi.

2. Pediatrik başlangıç ( 3 yaş ile puberte başlangıcı dönemleri arasi).

3. Belirtilerin aniden başlaması veya belirtilerde dramatik alevlenmelerle karakterize bir gidişin olması.

4. Belirtilerin başlangıcı veya alevlenmesi ile A grubu betahemolititk streptokok enfeksiyonu arasinda zamansal bir ilişkinin varlığı.

5. Alevlenme sırasında anormal nörolojik bulguların (hiperaktivite, koreiform hareketler, tikler) varlığı.

görülmekle birlikte, erkeklerde daha sık (2.6:1) görüldüŭgü belirtilmiştir. PANDAS'ta sık görülen obsesyonlar arasinda kontaminasyon obsesyonları, kendine/başkalarına zarar verme obsesyonları, cinsel obsesyonlar ve dini obsesyonların bulunduğu; bunun yanında motor ve vokal tiklerin hastalarda görülebildiği belirtilmiştir. Ayrıca hastaların bu semptomlarının veya semptomlardaki alevlenmelerinin ani bir şekilde başladığı (belirli bir hafta veya gün) fakat yavaş bir şekilde kaybolduğu bu çalışmada vurgulanan noktalar arasındadir.

Streptokok enfeksiyonlarının çocuklar arasında yaygın olduğu, fakat nöropsikiyatrik semptomların yaygın olmadığ $\breve{g}_{1}$ bildirilmektedir ${ }^{(24)} . \mathrm{Bu}$ durum, bazı çocukların streptokok enfeksiyonu sonrası PANDAS olarak adlandırılan tablonun gelişimi için daha yatkın olup olmadığı sorusunun sorulmasina neden olabilecektir. Bu konuya 1şık tutabilecek bir çalışmada 54 PANDAS tanıl1 hastanın ebeveyn $(n=100)$ ve kardeşlerinde $(\mathrm{n}=57)$ tik ve OKB sıklığı $\operatorname{araştırılmıştır~}^{(25)}$. Bu çalışmada ebeveyn ve kardeşlerdeki tik ve OKB sıklığı, sağlıklı insanlar için bildirilenden daha yüksek bulunmuştur. Bu bulgu PANDAS olarak adlandırılan tablonun gelişimine genetik yatkınlığın katkıda bulunabileceği olasılığını akla getirmektedir.

\section{Laboratuvar}

Swedo ve ark.(5), çocuklardaki semptomların 
başlangıcı/alevlenmesi ile AGBHS enfeksiyonu arasındaki ilişkinin saptanması için boğaz kültürü ve streptokoklara karşı oluşan antikorları (ASO, anti-DNaz B) kullanmışlardır. Fakat tek bir semptom alevlenmesi sırasında alınan kan örneğinde saptanan antistreptokokal antikor titresi yüksekliğinin, PANDAS tanısı için yeterli olmayacağını vurgulamışlardır. Zira bu antikor titrelerinin enfeksiyondan aylar sonra bile yüksek kalabildiği bilinmektedir. Dolayısıyla yeni geçirilen bir enfeksiyon tanısı için, başta antistreptokokal antikor titresinin ölçülmesi, birkaç hafta sonra tekrar ölçülerek antikor titresinde anlamlı bir artış olup olmadığının saptanması tavsiye edilmektedir(24). Bunun yanında, ASO antikor titresinin streptokok enfeksiyonundan 3-6 hafta sonra; anti-DNaz B antikor titresinin ise 6-8 hafta sonra en yüksek düzeyine ulaştığ bilinmektedir. Hastalardan kan örnekleri alınırken bu sürelerin göz önünde bulundurulması gerekmektedir.

\section{Yanıt bekleyen sorular}

PANDAS hipotezini araştıran çalışmalar incelendiğinde tartışmalı sonuçların ortaya çıktığı görülmektedir. Kimi çalışmalarda AGBHS enfeksiyonu ile OKB veya tik bozukluğu arasındaki ilişki gösterilmişken ${ }^{(26,27)}$ kimi çalışmalarda ise böyle bir ilişki saptanmamıştır ${ }^{(28,29)}$. Murphy ve ark.(26) 1998 ile 2000 yılları arasında, yaş ortalaması 7 olan, 12 çocuk hastaya PANDAS tanısı koymuşlardır. Tüm bu hastalarda "akut AGBHS tonsillofarenjiti” sonrası, ani başlangıçl1 OKB gözlendiğini vurgulamışlardır. Aynı araştırmacılar, çalışmalarında AGBHS enfeksiyonu tanısı için kültür, hızlı antijen saptama testi veya serolojik testler kullandıklarını belirtmiş, enfeksiyonun tedavisi için 5 hastaya penisilin, 1 hastaya amoksisilin/klavulanik asit, 6 hastaya ise sefalosporin grubu antibiyotik uyguladıklarından bahsetmişlerdir. Antibiyotik tedavisi sonrası, hastaların nöropsikiyatrik semptomlarının kaybolduğunu vurgulamışlardır. Cardonna ve ark. ${ }^{(30)}$ tik bozukluğu olan 150 çocuk ile, sağlıklı 150 kişilik kontrol grubunu dahil ettikleri bir olgu-kontrol çalışması yapmışlardır. Tik bozukluğu bulunan hasta grubundaki ortalama ASO titresini, kontrol grubundaki ortalama ASO titresinden istatistiksel olarak anlamlı olacak şekilde yüksek bulduklarını belirtmişlerdir. Ayıca, tik bozukluğu olan hasta grubunu kendi içerisinde incelediklerinde, tik bozukluklarının şiddetiyle ASO titrelerinin yüksekliği arasında pozitif bir korelasyon bulmuşlardır.

Luo ve ark. ${ }^{(28)}$ ise yaşları 7 ile 17 arasında değişen OKB ve/veya Tourette sendromu tanılı 47 hasta (37'si Tourette sendromu, 27'si OKB, 17'si hem Tourette sendromu hem OKB hastasi) ile sağlıklı 19 kişilik kontrol grubunu çalışmalarına dâhil etmişlerdir. İlk olarak hasta ve kontrol gruplarını D8/17 belirteci yönünden karşılaştırdıklarında; "Bu belirtece sahip B lenfosit oranının" hasta grubunda, kontrol grubuna göre anlamlı şekilde daha yüksek olduğunu belirtmişlerdir. Bununla birlikte, 30 hasta ile 17 kişilik kontrol grubunu ileriye yönelik izleyebilmişler, hastalar ve kontrol grubunda meydana gelen yeni AGBHS enfeksiyon sayılarını yıllık olarak hesaplamışlar fakat arada anlamlı bir fark bulamamışlardır. Ayrıca ileriye yönelik izledikleri 30 kişilik hasta grubunun "nöropsikiyatrik semptomlarındaki akut alevlenme sayılarını" da yıllık olarak hesaplamışlardır. Çalışmalarında, yeni geçirilen AGBHS enfeksiyonları ile 'nöropsikiyatrik semptomlardaki akut alevlenmeler' arasındaki ilişkiyi rastlantısal bir ilişkiden daha anlamlı bulmamışlardır. Diğer bir deyişle, AGBHS enfeksiyonlarının açık bir şekilde nöropsikiyatrik semptom alevlenmelerini tetiklediğini gösterememişlerdir. Bunun yanında, yalnızca AGBHS'lere özgül bir otoimmün patogenez sonucu OKB ve tik bozukluğunun oluştuğu kanıtlanamamıştır ${ }^{(31)}$. Zira Mycoplasma pneumoniae $^{(32)}$, Borrelia burgdorferi ${ }^{(33)}$ ve herpesviruslarla $^{(34)}$ Tourette sendromu ilişkisini gösteren çalışmalar mevcuttur. Örneğin, Müller 
ve ark. ${ }^{(32)}, 29$ Tourette sendromu hastas1 ile 29 kişilik kontrol grubunu çalışmalarına dâhil etmişlerdir. On yedi Tourette sendromu hastas1nın serumlarında $M$. pneumoniae'ya karşı yüksek titrede antikor saptarken yalnızca 1 adet kontrol grubu hastasında yüksek titrede anti-M. pneumoniae antikoru saptamışlardır. M. pneumoniae'nın tik bozukluklarının etiyolojisinde, hesaba katılması gereken bir etken olduğunu vurgulamışlardır. Ayrıca AGBHS enfeksiyonu tarafindan "anoreksiya nervoza"(35) ve "akut dissemine ensefalomiyelit (ADEM)"(36) gibi, OKB ile tik bozukluğundan daha farklı psikiyatrik ve nörolojik bozuklukların tetiklenebileceğini gösteren çalışmalar vardır. Bu bilgiler 1şı̆̆ında PANDAS'ın özgül bir klinik terim olup olmadığının sorgulanması ve tanı kriterlerinin yeniden gözden geçirilmesi doğru bir yaklaşım olabilecektir.

\section{Tedavi}

PANDAS'1n klinik tanısı ve patofizyolojisindeki bazı belirsizlikler nedeniyle, tedavisi ile ilgili belirsizlik de devam etmektedir. Bununla birlikte, PANDAS'ın ilaçla tedavisine ilişkin genellikle olgu bildirimlerine dayanan veriler mevcuttur ${ }^{(4)}$. Penisilin profilaksisinin ARA'daki alevlenmeleri azalttı $\breve{g}_{1}$ bilinmektedir. Dolayısıyla Sydenham koresi ve PANDAS patofizyolojisindeki benzerlik nedeniyle penisilin profilaksisinin PANDAS'lı hastalardaki nöropsikiyatrik alevlenmeleri azaltabileceği düşünülmüştür ${ }^{(37)}$. Snider ve ark. ${ }^{(38)}$ tarafından yapılan çalışmada, penisilin veya azitromisin kullanılarak uygulanan profilaksinin PANDAS'taki nöropsikiyatrik alevlenmeleri azalttığı gösterilmiştir. PANDAS tanılı 37 çocuğu kapsayan sekiz aylık, çift-kör bir çalışmada ise penisilin profilaksisinin plasebodan farklı olmadığı ortaya konulmuştur ${ }^{(39)}$.

"PANDAS post-streptokokal otoimmün bir hastalıksa, hastalar plazma değişimi veya IVIG tedavisine yanıt verebilir" düşüncesiyle yapılan ve 29 hastanın dâhil edildiği bir çalışma da mevcuttur. $\mathrm{Bu}$ çalışmada 10 hasta plasebo grubuna dâhil edilmiş, 10 hastaya plazma değişimi tedavisi, 9 hastaya ise IVIG tedavisi uygulanmıştır. Çalışma sonucunda hem plazma değişimi hem de IVIG tedavisinin semptomları azaltmada etkili olduğu gösterilmiştir ${ }^{(13)}$.

Ayrıca 9 yaşındaki PANDAS tanılı bir erkek çocuğun tonsillektomi sonrası semptomlarının kaybolduğunun gösterildiği bir olgu raporu ${ }^{(40)}$ ile PANDAS tanılı iki kardeşin semptomlarının yine tonsillektomi sonrası gerilediğinin gösterildiği bir olgu raporu da mevcuttur ${ }^{(41)}$.

\section{Sonuç}

PANDAS hipotezinin iyi tanımlanmış, farklı ve özgül bir tablo olup olmadığg hâlen belirsizliğini korumaktadır. Hastaların immünomodülatör tedavilere yanıt vermesi, PANDAS hipotezinin patogenezinde immün sistemin rolü olabileceğini göstermektedir. AGBHS dışındaki farklı mikrobiyal etkenlerin de PANDAS'taki nöropsikiyatrik semptomlara neden olabileceğinin gösterilmesi ve AGBHS ile şu anki PANDAS tanı kriterlerinde yer almayan farklı psikiyatrik/nörolojik bozuklukların ilişkisinin gösterilmesi, PANDAS tanımının ve tanı kriterlerinin sorgulanmasi gerektiği sonucunu doğurmaktadır.

Şu ana kadar yapılan çalışmaların genelde az sayıda hasta ile yapılan retrospektif çalışmalar olması, daha fazla sayıda hasta ve kontrol grubunun dâhil edildiği, iyi dizayn edilmiş, prospektif çalışmaların gerekliliğini ortaya koymaktadır.

\section{KAYNAKLAR}

1. Leblebicioğlu H. Akut tonsillofarenjit. In: Willke Topçu A, Söyletir G, Doğanay M, eds. Enfeksiyon Hastalıkları ve Mikrobiyolojisi. 3. bask1, İstanbul, 2008:731-41.

2. Sancak B. Streptococcus. In: Özkuyumcu C, ed. 
Hacettepe Mikrobiyoloji Serisi-1, Klinik Bakteriyoloji El Kitabı. 1. bask1, Ankara, 2009: 23-39.

3. Pons R. Sydenham's chorea, PANDAS, and other post-streptococcal neurological disorders. In: Frucht SJ, ed. Movement disorder emergencies, diagnosis and treatment. 2nd ed. New York: Springer, 2013:163-78. http://dx.doi.org/10.1007/978-1-60761-835-5_13

4. Bayraktar E, Kala Y. Obsesif-kompulsif bozukluğun etyopatogenezinde yeni bir boyut: PANDAS. Bull Clin Psychopharmacol 2000; 10:144-52.

5. Swedo SE, Leonard HL, Garvey M, et al. Pediatric autoimmune neuropsychiatric disorders associated with streptococcal infections: clinical description of the first 50 cases. Am J Psychiatry 1998; 155:264-71.

6. Kirvan CA, Swedo SE, Heuser JS, Cunningham MW. Mimicry and autoantibody-mediated neuronal cell signaling in Sydenham chorea. Nat Med 2003; 9:914-20. http://dx.doi.org/10.1038/nm892

7. Husby G, van de Rijn I, Zabriskie JB, Abdin ZH, Williams RC Jr. Antibodies reacting with cytoplasm of subthalamic and caudate nuclei neurons in chorea and acute rheumatic fever. $J$ Exp Med 1976; 144:1094110 .

http://dx.doi.org/10.1084/jem.144.4.1094

8. Garvey MA, Snider LA, Leitman SF, Werden R, Swedo SE. Treatment of Sydenham's chorea with intravenous immunoglobulin, plasma exchange, or prednisone. J Child Neurol 2005; 20:424-9. http://dx.doi.org/10.1177/08830738050200050601

9. Pavone P, Bianchini R, Parano E, et al. Anti-brain antibodies in PANDAS versus uncomplicated streptococcal infection. Pediatr Neurol 2004; 30:10710.

http://dx.doi.org/10.1016/S0887-8994(03)00413-2

10. Dale RC, Heyman I, Giovannoni G, Church AW. Incidence of anti-brain antibodies in children with obsessive-compulsive disorder. Br J Psychiatry 2005; 187:314-9. http://dx.doi.org/10.1192/bjp.187.4.314

11. Singer HS, Loiselle CR, Lee O, Minzer K, Swedo S, Grus FH. Anti-basal ganglia antibodies in PANDAS. Mov Disord 2004; 19:406-15. http://dx.doi.org/10.1002/mds.20052

12. Dale RC, Church AJ, Candler PM, Chapman M, Martino D, Giovannoni G. Serum autoantibodies do not differentiate PANDAS and Tourette syndrome from controls. Neurology 2006; 66:1612. http://dx.doi.org/10.1212/01.wnl.0000226832.36908.4c

13. Perlmutter SJ, Leitman SF, Garvey MA, et al. Therapeutic plasma exchange and intravenous immunoglobulin for obsessive-compulsive disorder and tic disorders in childhood. Lancet 1999; 354: 1153-8. http://dx.doi.org/10.1016/S0140-6736(98)12297-3

14. Hoffman KL, Hornig M, Yaddanapudi K, Jabado O, Lipkin WI. A murine model for neuropsychiatric disorders associated with group A beta-hemolytic streptococcal infection. J Neurosci 2004; 24:1780-91. http://dx.doi.org/10.1523/JNEUROSCI.0887-03.2004

15. Brimberg L, Benhar I, Mascaro-Blanco A, et al. Behavioral, pharmacological, and immunological abnormalities after streptococcal exposure: a novel rat model of Sydenham chorea and related neuropsychiatric disorders. Neuropsychopharmacology 2012; 37:2076-87. http://dx.doi.org/10.1038/npp.2012.56

16. Cuningham MW. Molecular mimicry, autoimmunity and infection in the pathogenesis of rheumatic fever. International Congress Series 2006; 1289:14-9. http://dx.doi.org/10.1016/j.ics.2005.12.004

17. Swedo SE, Leonard HL, Mittleman BB, et al. Identification of children with pediatric autoimmune neuropsychiatric disorders associated with streptococcal infections by a marker associated with rheumatic fever. Am J Psychiatry 1997; 154:110-2. http://dx.doi.org/10.1176/ajp.154.1.110

18. Murphy TK, Goodman WK, Fudge MW, et al. B lymphocyte antigen D8/17: a peripheral marker for childhood-onset obsessive-compulsive disorder and Tourette's syndrome? Am J Psychiatry 1997; 154:402-7. http://dx.doi.org/10.1176/ajp.154.3.402

19. Morer A, Vi-as O, Lázaro L, Bosch J, Toro J, Castro J. D8/17 monoclonal antibody: an unclear neuropsychiatric marker. Behav Neurol 2005; 16:1-8. http://dx.doi.org/10.1155/2005/795343

20. Inoff-Germain G, Rodríguez RS, Torres-Alcantara S, Díaz-Jimenez MJ, Swedo SE, Rapoport JL. An immunological marker (D8/17) associated with rheumatic fever as a predictor of childhood psychiatric disorders in a community sample. J Child Psychol Psychiatry 2003; 44:782-90.

http://dx.doi.org/10.1111/1469-7610.00163

21. Moretti G, Pasquini M, Mandarelli G, Tarsitani L, Biondi M. What every psychiatrist should know about PANDAS: a review. Clin Pract Epidemiol Ment Health 2008; 4:13. http://dx.doi.org/10.1186/1745-0179-4-13

22. Giedd JN, Rapoport JL, Kruesi MJ, et al. Sydenham's chorea: magnetic resonance imaging of the basal ganglia. Neurology 1995; 45:2199-202. http://dx.doi.org/10.1212/WNL.45.12.2199

23. Giedd JN, Rapoport JL, Garvey MA, Perlmutter S, Swedo SE. MRI assessment of children with obsessive-compulsive disorder or tics associated with streptococcal infection. Am J Psychiatry 2000; 157:281-3.

http://dx.doi.org/10.1176/appi.ajp.157.2.281

24. de Oliveira SK. PANDAS: a new disease? J Pediatr (Rio J) 2007; 83:201-8. http://dx.doi.org/10.2223/JPED.1615

25. Lougee L, Perlmutter SJ, Nicolson R, Garvey MA, Swedo SE. Psychiatric disorders in first-degree relatives of children with pediatric autoimmune neuropsychiatric disorders associated with streptococcal infections (PANDAS). J Am Acad Child Adolesc Psychiatr 2000; 39:1120-6. 
http://dx.doi.org/10.1097/00004583-200009000-00011

26. Murphy ML, Pichichero ME. Prospective identification and treatment of children with pediatric autoimmune neuropsychiatric disorder associated with group A streptococcal infection (PANDAS). Arch Pediatr Adolesc Med 2002; 156:356-61.

http://dx.doi.org/10.1001/archpedi.156.4.356

27. Giulino L, Gammon P, Sullivan K, et al. Is parental report of upper respiratory infection at the onset of obsessive-compulsive disorder suggestive of pediatric autoimmune neuropsychiatric disorder associated with streptococcal infection? J Child Adolesc Psychopharmacol 2002; 12:157-64. http://dx.doi.org/10.1089/104454602760219199

28. Luo F, Leckman JF, Katsovich L, et al. Prospective longitudinal study of children with tic disorders and/or obsessive-compulsive disorder: relationship of symptom exacerbations to newly acquired streptococcal infections. Pediatrics 2004; 113:e578-85. http://dx.doi.org/10.1542/peds.113.6.e578

29. Perrin EM, Murphy ML, Casey JR, et al. Does group A beta-hemolytic streptococcal infection increase risk for behavioral and neuropsychiatric symptoms in children? Arch Pediatr Adolesc Med 2004; 158:848-56. http://dx.doi.org/10.1001/archpedi.158.9.848

30. Cardona F, Orefici G. Group A streptococcal infections and tic disorders in an Italian pediatric population. $J$ Pediatr 2001; 138:71-5. http://dx.doi.org/10.1067/mpd.2001.110325

31. Shulman ST. Pediatric autoimmune neuropsychiatric disorders associated with streptococci (PANDAS): update. Curr Opin Pediatr 2009; 21:127-30. http://dx.doi.org/10.1097/MOP.0b013e32831db2c4

32. Müller N, Riedel M, Blendinger C, Oberle K, Jacobs E, Abele-Horn M. Mycoplasma pneumoniae infection and Tourette's syndrome. Psychiatry Res 2004; 129: 119-25. http://dx.doi.org/10.1016/j.psychres.2004.04.009

33. Riedel M, Straube A, Schwarz MJ, Wilske B, Müller
N. Lyme disease presenting as Tourette's syndrome. Lancet 1998; 351:418-9. http://dx.doi.org/10.1016/S0140-6736(05)78357-4

34. Turley JM. Tourette-like disorder after herpes encephalitis. Am J Psychiatr 1988; 145:1604-5. http://dx.doi.org/10.1176/ajp.145.12.1604a

35. Sokol MS. Infection-triggered anorexia nervosa in children: clinical description of four cases. $J$ Child Adolesc Psychopharmacol 2000; 10:133-45. http://dx.doi.org/10.1089/cap.2000.10.133

36. Dale RC, Church AJ, Cardoso F, et al. Poststreptococcal acute disseminated encephalomyelitis with basal ganglia involvement and auto-reactive antibasal ganglia antibodies. Ann Neurol 2001; 50:588-95. http://dx.doi.org/10.1002/ana.1250

37. Macerollo A, Martino D. Pediatric Autoimmune Neuropsychiatric Disorders Associated with Streptococcal Infections (PANDAS): An evolving concept. Tremor Other Hyperkinet Mov (N Y) 2013; 3:1-13.

38. Snider LA, Lougee L, Slattery M, Grant P, Swedo SE. Antibiotic prophylaxis with azithromycin or penicillin for childhood-onset neuropsychiatric disorders. Biol Psychiatry 2005; 57:788-92.

http://dx.doi.org/10.1016/j.biopsych.2004.12.035

39. Garvey MA, Perlmutter SJ, Allen AJ, et al. A pilot study of penicillin prophylaxis for neuropsychiatric exacerbations triggered by streptococcal infections. Biol Psychiatry 1999; 45:1564-71. http://dx.doi.org/10.1016/S0006-3223(99)00020-7

40. Batuecas Caletrío A, Sánchez González F, Santa Cruz Ruiz S, Santos Gorjón P, Blanco Pérez P. PANDAS Syndrome: a new tonsillectomy indication? Acta Otorrinolaringol Esp 2008; 59:362-3. http://dx.doi.org/10.1016/S0001-6519(08)75557-2

41. Orvidas LJ, Slattery MJ. Pediatric autoimmune neuropsychiatric disorders and streptococcal infections: role of otolaryngologist. Laryngoscope 2001; 111:1515-9.

http://dx.doi.org/10.1097/00005537-200109000-00005 